\title{
MODERN EDUCATIONAL TREATMENT OF DEAFNESS
}

$U^{2}$ NTIL recently there has been less investigation of hearing and of auditory perception than of vision and visual perception. Modern technological advances have made it possible for workers in a number of fields to gain much new knowledge about hearing. The International Congress on the Modern Educational Treatment of Deafness, which was held in the University of Manchester during July 15-23, was attended by more than 1,000 members from forty-one countries and was the largest of its kind ever to be held. It was distinguished also for its comprehensive and eclectic character. Papers on recent advances in the physiology of hearing, the pathology and causation of deafness in childhood, experimental phonetics, psycho-acoustics and audiology and the educational treatment of deafness attracted a 90 per cent attendance throughout the duration of the Congress. Audiences that included leading medical consultants and authorities on electro-acoustics and many outstanding educators of the deaf from almost all parts of the world followed papers and demonstrations of work in each others' fields with the closest attention.

The view was frequently expressed and evidently widely accepted that new scientific data about hearing are increasingly important and indeed basic to the treatment of deafness in childhood, and that the teamwork of experts in all relevant fields which is already in operation in certain centres constitutes a necessary practical approach.

Dr. Hallowell Davis, so long well-known for outstanding experimental studies in audiology at Harvard University and the Central Institute for the Deaf, St. Louis, reported that the electron microscope has now revealed many details of structure of the sense organ of the ear. The 'hairs' on the sensory hair cells of the cochlea now stand out clearly. There are considerable and probably important structural differences between the internal and external hair cells. An alternatingcurrent output-the familiar cochlea microphoniccomes from the external hair cells, while a direct current comes from the internal hair cells. The internal hair cells seem to resist the action of poisonous drugs and the mechanical stresses of high-intensity sound more successfully than the external hair cells, which appear to be more sensitive, more specialized and relatively recent in origin. The external hair cells make possible the detection of extremely faint sounds. Small differences in the times of arrival of individual sound waves at our two ears are detected by the external hair cells and the fibres connected to them and are one basis for our localization of the source of sound in the external world.

Microchemical studies of the fluids of the inner ear show that the endolymph within the membranous labyrinth is a tissue fluid of unique chemical composition. It has a high concentration of sodium. It has not yet proved possible to relate the possible physiological and neurological abnormalities that may be represented by recruitment and by Ménière's disease to the new physiological findings of chemistry and electro-physiology. An unexpected finding has been the demonstration of a bundle of nerve fibres that runs from the brain stem to the sense organs. Galambos has demonstrated that appropriate stimulation of this pathway (in cats under laboratory conditions) reduces the sensitivity of the ear.

Prof. Ormerod (Institute of Laryngology and Otology, University of London), in a paper on the pathology of congenital deafness, defined deafness in the very young child as due to failure to develop of some part of the auditory mechanism, or to a degeneration or a disturbance of some part, already developed, of this system. The factor interfering with the development of the ear must be operative during the first half of the period of gestation. There may be complete failure to develop of either acoustic or static parts of the internal ear. The basal coil of the cochlea may take shape but not the middle and apical turns. In the commoner form of congenital change the bony labyrinth is perfectly formed, the membranous and sensory vestibular organ is fully developed and functioning, but in the cochlea the scala media is usually collapsed and the organ of Corti is represented by a small heap of undifferentiated cells. Not all the children who suffer from congenital deafness are totally deaf, but as shown by Whetnall, the great majority have some islands of hearing and may be described as sub-totally deaf. (A similar finding has been reported from Manchester.)

Mr. Harrison, in a paper on the etiology of deafness in childhood, and Dr. Watson, dealing with factors affecting the successful use of hearing aids by deaf children, reported some results of a collaborative project for which a joint team of senior members of the staffs of the Manchester Department of Education of the Deaf and of Otolaryngology have been responsible, for a number of years, with the support of the Medical Research Council. In certain cases of deafness in childhood, for example, of malformation of the external and middle ear, capacity to hear had been improved after operative treatment, by contrast with cases of deafness associated with a history of kernicterus, which are not amenable to treatment. Familial perceptive deafness was characterized by a flattish type of audiogram, with hearing losses of about 80 decibels and by pure-tone determinations indicative of severe high-tone loss.

Dr. Goodhill (Los Angeles), in a paper given by means of a sound-recording, described recent surgical advances involving many procedures for reconstituting the middle ear, in children as well as in adults, with the view of enabling transmission of sound energy to the cochlea.

Results of systematic research on the capacity of children to benefit from the use of hearing aids were reported in several papers. Prolonged studies of groups of children in different categories of auditory impairment were stated by Dr. Watson and by Dr. Hudgins (Clarke School for the Deaf, Massachusetts) to have shown that no deduction about capacity to hear speech can be made from the pure-tone audiogram alone. In the joint investigation at the University of Manchester it had been demonstrated that some cases of perceptive deafness and most cases of conductive deafness could discriminate speech. 
As regards profoundly deaf children, a study of fifty pupils of the Clarke School who were profoundly deaf, over a five-year period had shown that their speech perception scores, when tested in the condition of listening with a hearing aid, and looking, were significantly higher than in the condition of lip-reading alone, and that the scores consistently improved in both conditions.

Prof. Bordley and Prof. Hardy (Baltimore) reported that since the Hearing and Speech Center of the Johns Hopkins Medical Institutions was established in 1947, intensive medical and neurological studies of children had led to a concept of hearing problems as no longer centred principally in the ear and naso-pharynx, nor in the family background. Approximately 70 per cent of the pre-school age children referred to the Hearing and Speech Center gave evidence of central disorders of trauma or mal-development at the level of the brain, with or without peripheral involvement.

A valuable paper on hearing aids was given by Dr. Littler (Medical Research Council, London), who described the peculiar problems that arise when attempts are made to equalize frequency response of the whole aid, with its three elements of microphone, amplifier and reproducer, by the combination of selective response in two different bands of sensitivity of microphone and reproducer.

Mr. Fant (Stockholm), discussing the acoustics of speech, described intensive studies of vowel articulation which have resulted in a three-parameter specification of the vocal tract configuration. $\mathrm{He}_{\Theta}$ demonstrated speech that was artificially produced. This paper was appropriately followed, at a later session, by one in which Mr. John (Department of Education of the Deaf, Manchester) reported experiments that have shown the detrimental effects of reverberation and noise in rooms on the intelligibility with which speech can be heard through hearing aids and the great deterioration in scores that accompanies increase in distance of speaker from microphone. The acoustics of rooms, in which the amount of reverberation that is present is completely tolerable to listeners with unimpaired binaural hearing, can offer the greatest difficulty to users of hearing aids. Reference was made to spectrographic studies that demonstrate the distortions of vowel and consonant formants that take place. Mr. Thomas, who has collaborated with Mr. John, read a paper on the application of their findings in architectural acoustics to the design and construction of schools for the deaf and the acoustical treatment of new schools, as now practised on their advice in many parts of the United Kingdom.

Closed-circuit television broadcasts were given during two sessions. The first was introduced by Dr. Irene Ewing, who described how the diagnostic practices of the Manchester department had grown out of her own direct and original study of the highly selective reactions to sounds made by normal very young children. Under her direction, screening tests of hearing suitable for children from four months to five years were given by health visitors from the public health departments of the City of Manchester and Caernarvonshire (in Welsh), to whom with some thousand others in many parts of the United Kingdom, she had given special training. Parent guidance and the results of home training, including the use of hearing aids, with children aged from eight months to five years, were shown by Dr. Ian Taylor and Mrs.
Beaman. In a paper on this subject, Prof. Huizing (Groningen) gave results of experiments that demonstrated how a home-trained child, wearing a hearing aid from the age of sixteen months, achieved a more rapid growth of expressive language than children who had audiological treatment and conventional oral training from their fourth birthdays onwards. Prof. Huizing stressed the importance of auditory feed-back in the linguistic development of deaf children, that is, of enabling them to hear their own voices, and so far as possible their own speech.

In a short article it is possible only to mention a few of the many excellent contributions made by teachers of the deaf serving on the staffs of schools, and educational psychologists. Among the most notable was a demonstration, introduced by Father van Uden, of some methods and results of training profoundly deaf children to respond to the sound of speech and music, when very loudly reproduced. Some pupils of the Institute for the Deaf, Sint Michielsgestel, aged 11-12 years, all of whom were profoundly or sub-totally deaf, were given a lesson in the course of which they were seen composing 'play-songs' or simple melodies to which they afterwards danced. Then a similarly constituted group of girls aged 13-18 years showed their notable capacity to dance ballet to music reproduced from a battery of specially designed loud-speakers, at an average peak sound-level of 95 decibels above 0.0002 dynes per sq. centimetre. The late Dr. Becking with Father van Uden made experiments that led them to conclude that profoundly deaf children can learn to perceive feelings of vibration in the body, in response to abnormally loud sound and that these feelings are an introduction to, and an enrichment of, sound-perception in the ears, the basic principle being a feed-back between sound-perception and bodily movements.

Equally significant, in a different way, was a demonstration by closed-circuit television in which severely, profoundly and sub-totally deaf pupils from the Nursery-Infant Branch of the Royal Schools for the Deaf, Manchester, aged 7-8 years, under Miss Goldsack, showed remarkable spontaneity and capacity to express themselves verbally, with a standard of general knowledge that would have done credit to a better than average class of unhandicapped pupils. They were taught in a classroom wired for induction, which enables them to move about freely without losing the teacher's voice. Five of them had had home training. Demonstrations were given by older boys and girls, using similar equipment, from the Royal Cross Schools, Preston, and the Braidwood Schools, Birmingham. Dr. Schmaehl (Dortmund) and Mr. Mikaelian (Moscow) reported extensive use of inductance systems in their countries.

Attention was frequently directed to problems in the social development of deaf children. Miss Numbers (Clarke School, Massachusetts) and Mr. Askew, principal of the English Grammar School for the Deaf, gave details of the wide ranges of occupations that are being followed by well-educated ex-pupils of good ability. Dr. Buchli, director, Royal Institute for the Deaf, Groningen, stated that he had found that children who could not be day-pupils developed more normally when living with foster-parents than in a residential special school. Dr. Murphy (Melbourne) and Dr. Silverman, director, Central Institute for the Deaf, St. Louis, referred to deaf men and women who seek social life among others who are 
similarly handicapped. Dr. O'Connor, superintendent, Lexington School for the Deaf, reported use of tests and procedures for evaluating the capacity of boys and girls handicapped by deafness to benefit from attendance at ordinary schools. Mrs. Miller (Clarke School) described some methods of social training for senior pupils. An important paper by Prof. Lewis (University of Nottingham) on language perception and reasoning was supported by one from Dr.
Morosova (Moscow), in which she described capacity to use words in thinking as a leading determinant of cognitive activity. Several speakers, including the writer of this article, discussed the achievement of this capacity as a factor in the social development of deaf children, and the deviation of their mental growth from normal when it is begun later than among children who are not deaf.

A. W. G. EwING

\section{NATURE AND GENETICAL CONTROL OF RESISTANCE IN LIVING ORGANISMS}

$\mathrm{T}$ HE nature and genetical control of resistance in living organisms was considered at a joint session on September 1 of Sections $D$ and $K$ (Zoology and Botany) of the British Association at the Glasgow meeting. The topics were disease resistance in plants and animals, insecticide resistance in mosquitoes and drug resistance in bacteria.

In the opening paper Dr. P. R. Day (John Innes Horticultural Institution) outlined the types of genetical control of resistance to pathogens in higher plants. These range from the single, usually dominant, gene through complementary action of two or more genes to polygenic control. There is a similar pattern in the genetic control of virulence in fungal pathogens selected by cultivation of resistant crop varieties. At the single-gene level this has led to the suggestion of a gene-for-gene relationship whereby the outcome of host infection by a pathogen depends on the alleles present at complementary loci in both organisms. A resistance gene in the host is only effective if there is a corresponding avirulence gene in the pathogen. An example of how the gene-for-gene concept may be applied comes from work at the University of Wisconsin on the inheritance of avirulence among a group of strains of Venturia inaequalis (apple scab) on seven apple varieties. The genes for avirulence were identified and separated in recombinant stocks. From the results of inoculations it was possible to estimate how many genes for resistance were present in each apple variety and which genes for resistance were common to two or more varieties. The interaction of gene products of the host and pathogen enables the host to recognize that the pathogen is avirulent. This recognition triggers secondary reactions which kill or limit the pathogen growth. Mutants of Cladosporium fulvum (tomato leaf mould) and Melampsora lini (flax rust) can be obtained which presumably avoid the recognition reaction and are thus virulent on a particular host resistant to the original strains.

Miss C. E. Jackson (Ross Institute of Tropical Hygiene) described the appearance of resistance to chlorinated hydrocarbon insecticides (dieldrin, $\mathrm{BHC}$ and DDT) following their use to control natural populations of malaria-carrying anopheline mosquitoes. Laboratory studies showed that resistance to dieldrin in a strain of Anopheles gambiae from Northern Nigeria was some 800 times higher than that of wild-type insects of that species and was controlled by a partially dominant single gene. A discriminating dose of the insecticide enables hybrids to be distinguished from the homozygous resistant parent. DDT resistance in $A$. sundaicus from Java was controlled by a single recessive gene. In laboratory experiments it was possible to raise the level of tolerance of mosquitoes to insecticides by exposures to sublethal doses during twenty generations of larval selection. The level of tolerance achieved was never more than seven times that of the original stock and this fell when larval treatments were stopped. This 'vigour tolerance' may be associated with inversions found in the chromosomes of treated stocks. The importance of this problem is shown by the fact that resistance to the insecticides dieldrin, $\mathrm{BHC}$ and DDT and its analogues is now found in eleven countries in six species of mosquito. No example of simultaneous resistance to DDT and dieldrin or DDT and BHC has yet been proved.

Dr. Mary Barber (Postgraduate Medical School, London) described three types of drug resistance found in bacteria: drug tolerance, drug dependence and drug destruction. The first two types of resistance generally arise by mutation. Drug destruction is often due to formation of an adaptive enzyme such as penicillinase in some penicillin-resistant bacteria. The initiation of enzyme production by strains previously producing none probably results from mutation. The genetic transfer of drug resistance between cells can be accomplished in the laboratory by deoxyribonucleic acid extracts (transformation), by a virus vector (transduction) and by direct transfer of a bacterial chromosome, or parts of it, when cells are in contact (conjugation). The extent of these processes in Nature is unknown, although favourable conditions exist in the human flora or in the soil. The accumulation of drugresistant strains of Mycobacterium tuberculosis and Staphylococcus aureus in hospitals has become a major problem. A study of penicillin-resistant $S$. aureus carried in the noses of pupil midwives in a London hospital showed a rise from 24 per cent carrying such strains during their first two weeks in the hospital to 60 per cent after three months. Of the permanent hospital staff 90 per cent carried resistant S. aureus.

The most successful approach to the control of both bacteria and mosquitoes is likely to be the simultaneous use of two or more drugs or insecticides. This makes it less likely that resistant mutants will develop. Plant breeders also try to release new disease-resistant crop varieties having two or more different resistance genes for the same reason.

Dr. A. Kleczkowski (Rothamsted Experimental Station) surveyed resistance to virus diseases in animals and plants. Resistance in plants is in a special category because of the absence of any immunity reaction comparable to the antibodies of the $\gamma$-globulin fraction of animal serum proteins. 